\title{
Prototype Smart Parking Lift System Berbasis Arduino
}

\section{Prototype of Smart Parking Lift System in Arduino-Based}

\author{
Aprinal Adila Asril \& Popy Maria \\ Jurusan Teknik Elektro Politeknik Negeri Padang Kampus Limau Manis Padang \\ Telp. 0751-72590 Fax.0751-72576 Email: adila_asril@yahoo.co.id
}

\begin{abstract}
High number of vehicle theft and damaged vehicle caused climate factor such disasters on conventional garage has made an encouragement to the owners to decrease those risks. By using special access and by putting the garage down tothe basement can be trusted way to minimalized those risks above.

This system works by communicate RFID reader and infrared sensor an inputs. RFID reader MFRC522 has a role as authentication tool for vehicle owners by manifest their card identities to the system. Meanwhile the infrared sensors IR-FC51 work as the input of automatic system. All these inputs will be proceeded by Arduino Uno as smart system data processor and ended by the movement of the dc motor as the lift motor and LCD as the information displayer.

The registered owner card will get a special access to entering parking lot on basement, while the users that didn't have registered card has no access to enter. Inside the lift, there will be infrared sensors to detect the vehicle on the lift and automatically will moved the lift upside or downside.
\end{abstract}

Keywords: Arduino, Smart system, Parking, RFID, Infrared

\section{PENDAHULUAN}

Kendaraan merupakan suatu alat bagi manusia untuk dapat berpindah dari satu tempat ke tempat lain dengan memangkas waktu tempuh dan tenaga.

Namun pada saat ini kendaraan bukanlah suatu hal yang mustahil untuk dimiliki masyarakat umum. Berbagai kemudahan baik dalam bidang finansial maupun fitur yang ditawarkan sangat menarik minat masyarakat untuk memiliki kendaraan pribadi. Ditunjang dengan naiknya perekonomian, maka daya beli masyarakat terhadap kendaraan pribadi pun semakin meningkat, sehingga laju kencang daya beli masyarakat terhadap Sistem smart home yang akan dibuat pada penelitian ini dapat berfungsi sebagai peningkatan efektifitas penggunaan lahan untuk parkir dan keamanan kendaraan dirumah. Seringnya terjadi pencurian kendaraan dan tingginya angka bencana alam yang disebabkan faktor iklim di daerah padat pemukiman serta kurangnya tingkat sekuritas parkir garasi konvensional yang mengakibatkan kerugian secara materil maupun psikis bagi pemilik kendaraan.
Beberapa kasus tersebut melatarbelakangi tujuan pembangunan prototype parkir pintar pada system smart home ini. Dengan menggunakan kartu identitas elektronik sebagai media komunikasi dan pengamanan kendaraan, lift sebagai media pemindah, serta basement sebagai lahan parkir kendaraan, sistem parkir pintar ini akan sangat efektif digunakan pada rumah dengan kendaraan lebih dari satu unit. Parkir pintar ini tentunya dapat meminimalisir tingkat kejahatan pencurian kendaraan bermotor. Tak hanya itu, prototype ini diharapkan mampu membuktikan kelebihannya dari parker bawah tanah biasa dengan melindungi kendaraan dari gengguan seperti yang berasal dari faktor iklim.

Tujuan pembuatan penelitian ini adalah Pembuatan Prototype Smart Parking Lift System Berbasis Arduino yang merupakan salah satu penerapan Smart Home System yang berfungsi sebagai peningkatan efektifitas penggunaan lahan parkir dan sistem pengamanan parkir kendaraan bermotor. Prototype ini juga bertujuan untuk mengoptimalkan penggunaan RFID dan inframerah sebagai 
input pengontrolan lift serta merencanakan pembuatan mekanik yang efisien dan sesuai dengan peralatan yang digunakan.

Adapun manfaat dari penelitian ini adalah :

a. Menerapkan sebuah sistem smart home parking system yang mampu mengoptimalkan lahan parkir yang sempit dengan memindahkannya ke bawah permukaan tanah (basement).

b. Mengoptimalkan arduino pada sistem smart home sebagai pengontrol dan pengumpul data.

c. Mengembangkan ilmu pengetahuan di bidang kontrol otomatis dan pengetahuan tentang penerapannya dalam kehidupan nyata.

\section{METODOLOGI}

\section{Sistem Cerdas}

Sistem cerdas merupakan suatu ilmu metode kendali yang dikembangkan untuk mengembangkan karakteristik-karakteristik penting dari kecerdasan manusia. Karakteristik-karakteristik tersebut diantaranya adaptasi dan belajar, perencanaan di bawah suatu kondisi dengan ketidakpastian yang tinggi dan kemampuan menangani data dengan jumlah besar. [4]

Kendali cerdas mempunyai tingkattingkat, di mana pada tingkat yang paling bawah adalah kendali konvensional yang sifatnya presisi, yang mana kendali tersebut melakukan pengendalian secara rinci dan teliti berdasarkan masukan dari kendali pada tingkat yang lebih tinggi bersifat koordinatif dengan tingkat kepersisian yang lebih rendah. Dengan demikian sistem cerdas memiliki ciri kemampuan otonomi, yaitu memiliki kemampuan perencanaan yang lebih mandiri untuk melaksanakan tugas, dengan cara membagi tugas yang diberikan oleh pengguna sistem cerdas itu menjadi tugas-tugas yang lebih kecil. Tugas-tugas tersebut dikoordinasi oleh kendali dengan tingkat yang lebih tinggi agar tugas besar dapat diselesaikan dengan baik. [4].

Sistem cerdas mampu bertindak secara tepat pada sistem yang lingkungannya yang tidak menentu di mana tindakan itu akan meningkakan kemungkinan berhasil pada sub-tugas yang kemudian dengan fungsi koordinasi

akan mampu meningkatkan keberhasilan sistem secara umum.

Komponen utama dari kendali cerdas memiliki ciri-ciri [4]

1.Sistem cerdas minimal mampu mendeteksi lingkungan dan dapat mengambil keputusan serta pengendalian.

2. Sistem cerdas dengan tingkat yang lebih tinggi memiliki kemampuan mengenali suatu objek dan peristiwa, menyajikan suatu pengetahuan di model dunia serta memberikan alasan yang tepat tentang perencanaan masa depan.

3. Pada sistem yang lebih canggih lagi maka sistem akan mampu merasakan dan mengerti, dan memilih sesuatu dengan bijak, dan bertindak secara berhasil meskipun banyak terjadi perubahan lingkungan.

4. Sistem cerdas haruslah terus tumbuh dan berkembang baik dalam kemampuan mengatasi masalah maupun melalui pengumpulan pengetahuan, bagaimana memilahnya, dan kemudian memutuskan dan mengirimkan sinyal kendali. [4]

\section{Smart Home}

Smart home di definisikan sebagai tempat tinggal yang dilengkapi dengan komputasi data dan teknologi informasi yang dapat merespon kebutuhan penghuni rumah, bekerja dengan mengandalkan efisiensi, otomatisasi perangkat, kenyamanan, keamanan, penghematan, dan hiburan yang bisa didapatkan melalui manajemen teknologi dalam rumah dan koneksi ke dunia luar. Dalam operasinya, smart home dibantu oleh komputer untuk memberikan fasilitas-fasilitas yang diinginkan secara otomatis dan sudah teprogram. Perintah dan sistem kendali smart home dapat dilakukan dengan suara, remote kontrol dengan kendali jarak jauh, tepukan tangan, sensor, dan sebagainya. 


\section{Arduino Uno}

Arduino merupakan sebuah papan mikrokontroler yang bisa deprogram dengan mudah. Program di arduino disebut sketch. Arduino Uno adalah board sistem minimum dengan menggunakan microcontroller ATmega328 jenis AVR. Arduino Uno memiliki 14 digital input/output (6 diantaranya dapat digunakan untuk PWM output), 6 analog input, 16 $\mathrm{MHz}$ osilator kristal, USB connection, power jack, ICSP header dan tombol reset.[4] Bentuk fisik dan bagian-bagian dari Arduino Uno R3 tampak dari atas dapat dilihat pada gambar 1. dan gambar 2 . [3]

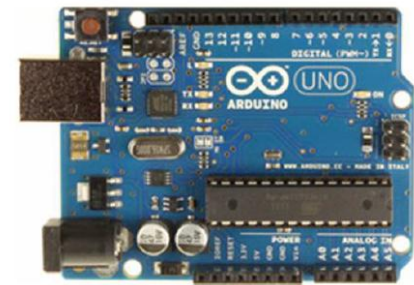

Gambar 1. Arduino Uno [3]

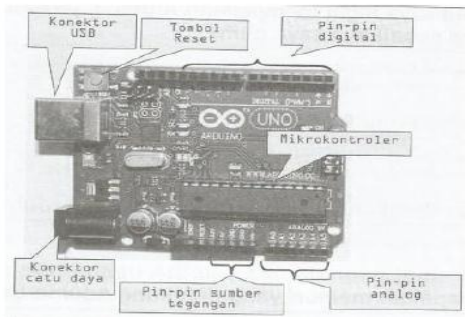

Gambar 2. Bagian-Bagian Arduino Uno [3]

\section{Radio Frequency Identification (RFID)}

RFID adalah singkatan dari Radio

Frequency Identification. RFID merupakan sistem pengenalan tanpa kabel melalui frekuensi radio yang dapat mengambil data tanpa harus bersentuhan seperti barcode dan magnetic card seperti ATM. Sebagai metode pengidentifikasian objek maka RFID dapat digunakan untuk menyimpan atau menerima data menggunakan alat bernama RFID tag atau transponder. [6 ]

\section{RFID Tag}

RFID Tag adalah alat yang akan dikenali oleh RFID reader. RFID tag pasif lebih banyak digunakan karena murah dan mempunyai ukuran lebih kecil. RFID tag dapat berupa perangkat read-only yang berarti hanya dapat dibaca saja ataupun perangkat read-write yang berarti dapat dibaca dan ditulis ulang untuk diperbaharui. RFID tag dapat dilihat pada gambar 3.:[6 ]

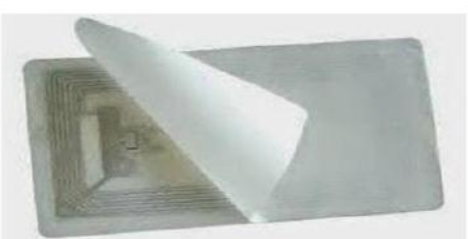

Gambar 3. RFID Tag [6]

RFID tag mempunyai dua bagian penting, yaitu:

1. IC atau kepanjangan dari Integrated Circuit

Berfungsi menyimpan dan memproses informasi, modulasi dan demodulasi sinyal RF, mengambil tegangan DC yang dikirim dari RFID reader melalui induksi, dan beberapa fungsi khusus lainya.

2. Antena

Berfungsi menerima dan mengirim sinyal RF.

\section{RFID Reader}

RFID reader merupakan alat pembaca RFID Tag. Jalur gelombang RFID yang paling banyak dipakai adalah jalur UHF ada frekuensi 865-868 MHz dan 902928 MHz. Kode yang ditulis pada tag berupa 96 bit data yang berisi 8 bit header, 28 bit nama organisasi pengelola data, 24 bit kelas objek

(misal untuk identifikasi jenis produk) dan 36 bit terakhir adalah nomor seri yang unik untuk tag. Kode tersebut dipancarkan melalui sinyal RF dengan urutan yang telah standar. Gambar 4. merupakan bentuk fisik RFID Reader. [6]

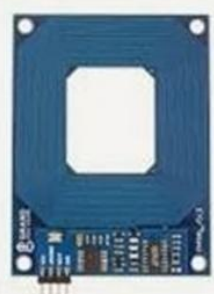

Gambar 4. RFID Reader [6] 
Tag dapat dibaca jika lewat di dekat pembaca, bahkan jika itu ditutupi oleh obyek atau tidak terlihat. Tag dapat dibaca dalam wadah, karton , kotak atau lainnya, dan tidak seperti barcode, RFID tag dapat sekaligus dibaca ratusan ID pada suatu waktu. RFID juga tahan air dan gesekan karena biasanya dikemas dalam chip yang dimasukkan kedalam bodi obyek yang dipasang RFID. [6]

\section{Sensor Inframerah}

Menurut Muvida (2010), sensor inframerah merupakan piranti yang mengubah besaran-besaran fisis seperti magnetik, radiasi, mekanik dan termal menjadi besaran listrik. Komponen utama pembentuk sensor adalah struktur sensor, teknologi manufaktur, dan algoritma pengolah sinyal, hal inilah yang menentukan kemampuan suatu sensor.

Sensor inframerah menggunakan catu daya $5 \mathrm{~V}$, berguna untuk mendeteksi halangan dengan memancarkan gelombang inframerah dan tidak terpengaruh oleh cahaya lampu maupun sinar matahari. Pada sensor inframerah ini terpasang satu pemancar dan satu penerima.

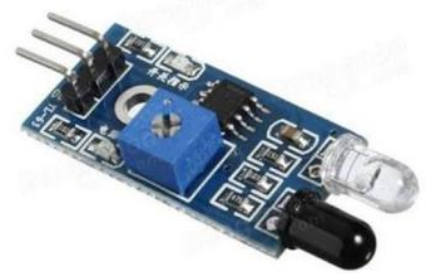

Gambar 5. Sensor Inframerah

\section{Liquid Crystal Display (LCD)}

LCD (Liquid Crystal Display) merupakan suatu piranti yang berfungsi sebagai tampilan. Terdapat dua jenis LCD, yaitu LCD karakter dan LCD grafik. LCD karakter digunakan diberbagai bidang misalnya alal-alat elektronik seperti televisi, kalkulator, atau pun layar komputer. Pada postingan aplikasi LCD yang dugunakan ialah LCD dot matrik dengan jumlah karakter 2 x 16. LCD sangat berfungsi sebagai penampil yang nantinya akan digunakan untuk menampilkan status kerja alat. Skema dan pin LCD dapat dilihat pada gambar 6 .

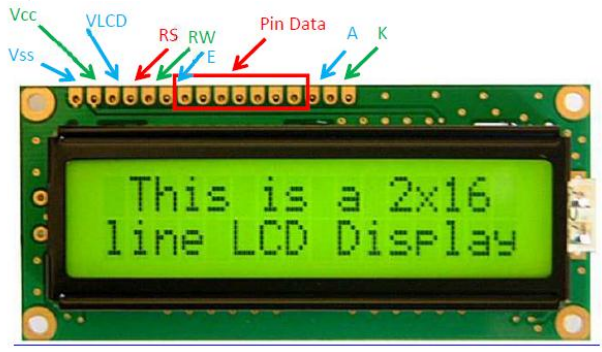

Gambar 6. Skema LCD 16 x 2. [6]

\section{Relay}

Relay adalah sebuah saklar yang di kendalikan oleh arus. Relay memiliki sebuah kumparan tegangan rendah yang dililitkan pada sebuah inti dan arus nominal yang harus dipenuhi output rangkaian pendriver atau pengemudinya. Arus yang digunakan pada rangkaian adalah arus DC. [1]. Relay adalah saklar elektronik yang dapat dikendalikan atau dikontrol dengan menggunakan perangkat elektronik lainnya. Sebuah relay tersusun atas kumparan, pegas, saklar (terhubung pada pegas), dan 2 kontak elektronik (normally close dan normally open). Pada gambar 7. merupakan bagian-bagian dan skematik Relay.

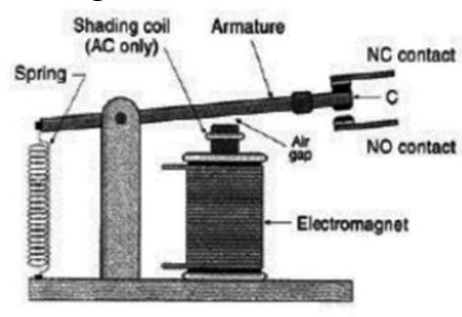

(a) Parts of the relay

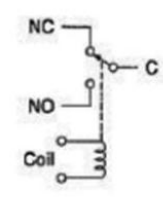

(b) A common schematic symbol

Gambar 7. Relay dan skematik Relay

Pada dasarnya prinsip kerja relay adalah ketika Coil mendapat energi listrik, maka akan timbul gaya elektromagnet yang akan menarik saklar yang berpegas, dan kontak elektronik akan berpindah posisi. Relay pada rangkaian elektronika biasanya digunakan sebagai suatu pengontrolan sistem bertegangan tinggi dengan tegangan yang kecil, sebagai contoh pada alat yang dibuat oleh penulis, relay digunakan untuk mengontrol (mematikan ataupun menyalakan) lampu dan pemanas air yang memiliki tegangan AC 220 volt, dengan 
menggunakan control dari arduino yang memiliki tegangan VCC hanya sebesar 5 volt DC.

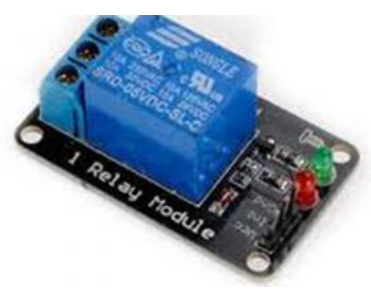

Gambar 8. Modul Relay

\section{Motor DC}

Motor DC adalah sebuah motor listrik yang mengubah energi listrik menjadi energi mekanik. Kebanyakan motor listrik beroperasi melalui interaksi medan magnet dan konduktor pembawa arus untuk menghasilkan kekuatan, meskipun motor elektrostatik menggunakan gaya elektrostatik. Pada motor DC kumparan medan disebut stator (bagian yang tidak berputar) dan kumparan jangkar disebut rotor (bagian yang berputar). Jika tejadi putaran pada kumparan jangkar dalam pada medan magnet, maka akan timbul tegangan (GGL) yang berubah-ubah arah pada setiap setengah putaran, sehingga merupakan tegangan bolak-balik. [2]

Motor DC sering dimanfaatkan sebagai penggerak pintu geser otomatis dan dalam rangkaian robot sederhana. Bagianbagian motor DC dapat dilihat pada gambar 8.

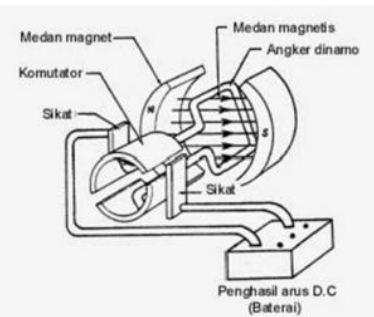

Gambar 9. Bagian-bagian motor DC. [2]

Pada Motor DC jika arus lewat pada suatu konduktor, timbul medan magnet di sekitar konduktor. Medan magnet hanya terjadi di sekitar sebuah konduktor jika ada arus mengalir pada konduktor tersebut. Arah medan magnet ditentukan oleh arah aliran arus pada konduktor. Dapat dilihat pada gambar 9 .

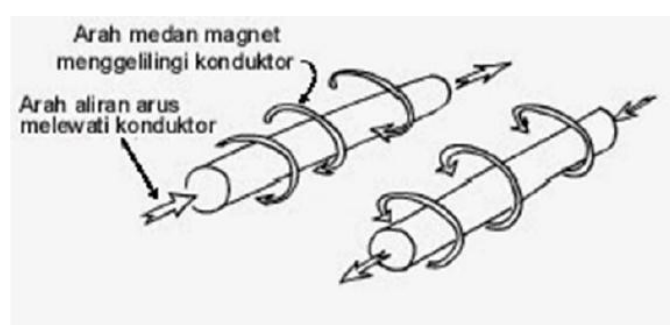

Gambar 10. Prinsip kerja motor DC [2]

\section{Buzzer}

Buzzer adalah sebuah komponen elektronika yang berfungsi untuk mengubah getaran listrik menjadi getaran suara. Pada dasarnya prinsip kerja buzzer hamper sama dengan loud speaker, jadi buzzer juga terdiri dari kumparan yang terpasang pada diafragma dan kemudian kumparan tersebut dialiri arus sehingga menjadi elektromagnet, kumparan tadi akan tertarik ke dalam atau keluar, tergantung dari arah arus dan polaritas magnetnya, karena kumparan dipasang pada diafragma maka setiap gerakan kumparan akan menggerakkan diafragma secara bolakbalik sehingga membuat udara bergetar yang akan menghasilkan suara. [7]

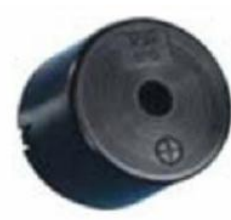

(a)

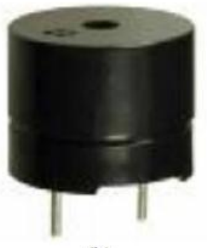

(b)
Gambar 11. (a) Bentuk fisik buzzer tampak atas

(b) Bentuk fisik buzzer tampak samping.

\section{Perancangan Dan Pembuatan Sistem Perancangan Prototype}

Pada sistem perancangan dan pembuatan prototype lift kendaraan ini diharapkan mampu membawa kendaraan naik dan turun dari dan ke arah basement dengan menggunakan akses kartu elektronik dan inframerah, sehingga efektifitas penggunaan lahan dan keamanan 
kendaraan dari faktor lingkungan dan kriminalitas dapat ditingkatkan.

Pada perancangan sistem ini meliputi perancangan perangkat perangkat keras (hardware), dan perangkat lunak (software).

Perancangan ini bertujuan untuk:

1. Menentukan cara kerja dari alat yang dirancang.

2. Menentukan komponen-komponen yang diperlukan.

3. Sebagai pedoman pembuatan alat.

4. Meminimalisir kesalahan dalam proses pembuatan alat.

5. Alat yang dihasilkan berfungsi dengan baik.

Perancangan sistem ini terdiri atas 3 tahap, yaitu:

1. Perancangan Sistem Keseluruhan.

2. Perancangan Perangkat Keras.

3. Perancangan Mekanik.

\section{Perancangan Sistem Keseluruhan}

Perancangan sistem bertujuan untuk merencanakan perangkat dan program yang akan diisikan ke dalam perangkat keras sehingga nantinya akan membentuk sebuah kontrol sistem cerdas. Pengerjaan tahap ini akan menentukan seperti apa penerapan skema yang telah direncanakan.

\section{A. Diagram Blok Sistem}

Diagram blok sistem merupakan salah satu bagian terpenting dalam perancangan dan pembuatan alat ini, karena dari diagram blok dapat diketahui prinsip kerja keseluruhan rangkaian. Tujuan lain diagram blok ini adalah memudahkan proses perancangan dan pembuatan pada masing-masing bagian, sehingga akan terbentuk suatu sistem yang sesuai dengan perancangan sebelumnya. Diagram blok sistem parkir cerdas dapat dilihat pada gambar 12.

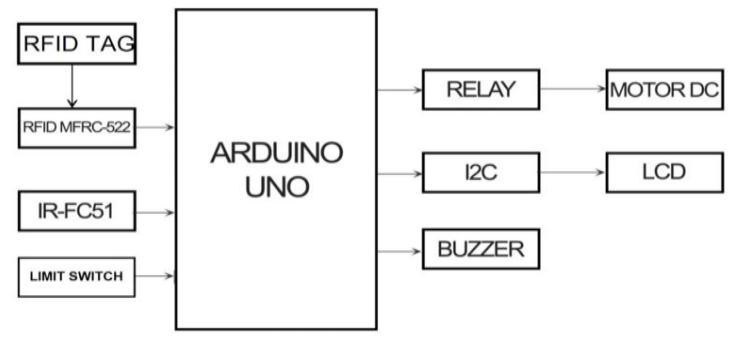

Gambar 12. Diagram Blok Keseluruhan Sistem

\section{B. Flowchart}

Flowchart adalah bagan dengan simbol-simbol tertentu yang menggambarkan urutan proses secara mendetail dan hubungan suatu proses dengan proses lainnya dalam suatu sistem. Flowchart nantinya akan mempengaruhi proses pembuatan program ke alat yang akan dibuat. Dari flowchart yang dibuat nantinya, proses penkgkodean program ke dalam mikrikontroler akan dimasukkan secara berurutan.

Pada prototype ini terdapat dua skema yang dijalankan, yaitu skema kendaraan masuk area parkir ke basement dan skema keluar area parkir dari basement. Oleh karena itu ada dua flowchart atau alur jalannya secara berurutan. Berikut lowchart pada prototype alat ini:

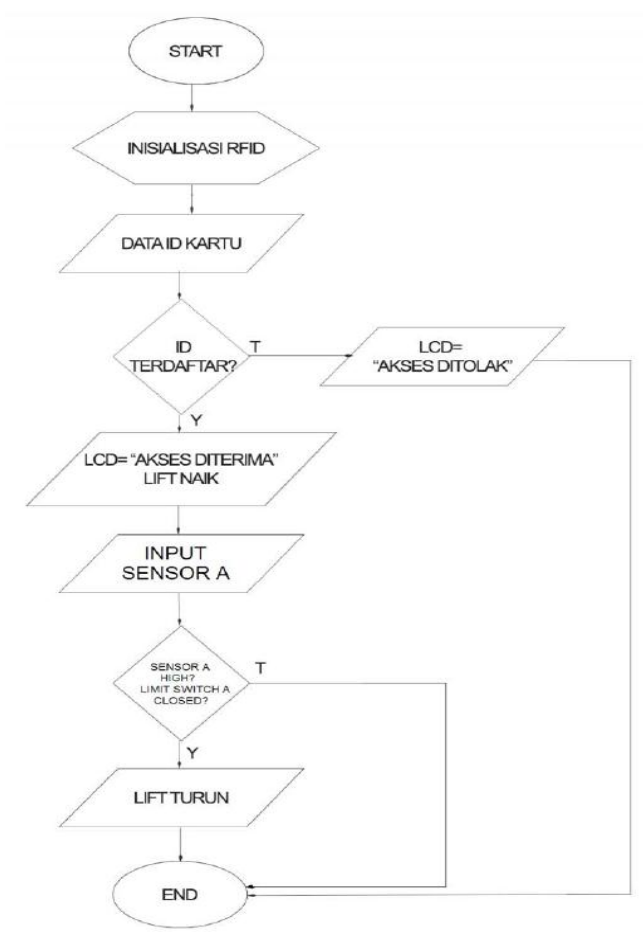

Gambar 13. Flowchart arah masuk kendaraan. 


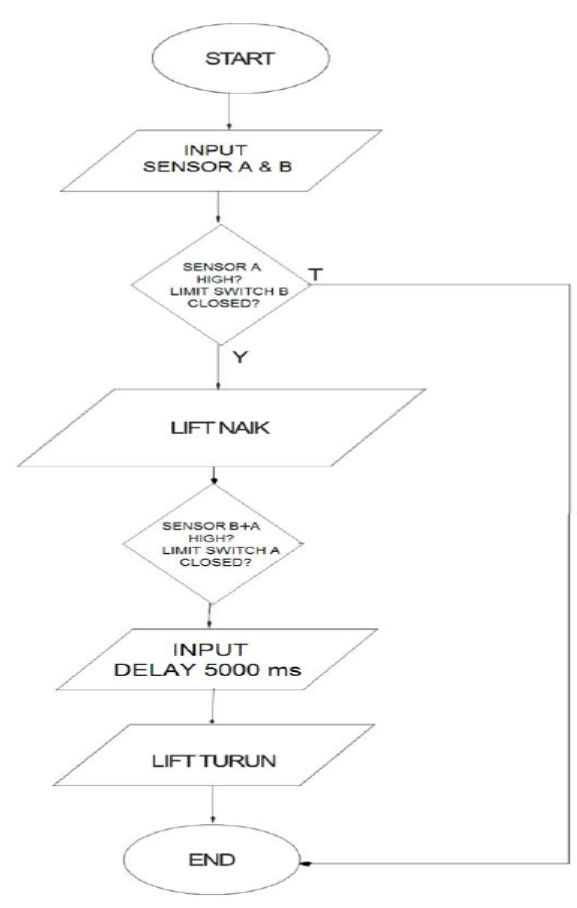

Gambar 14. Flowchart arah keluar kendaraan.

\section{Sistem Analisis}

Setelah data pengujian diperoleh, tahap selanjutnya adalah menganalisis data tersebut. Analisis dilakukan ada beberapa tahap sebagai langkah untuk memastikan apakah semua komponen penyususn prototype ini berjalan sesuai fungsinya, adapun tahap-tahap analisis sebagai berikut :

a. Analisis hasil Pengujian RFID

b. Analisis pengujian Sensor Inframerah

\section{HASIL DAN PEMBAHASAN}

\section{Hasil pengujian RFID}

Pengujian ini dilakukan agar dapat mengetahui apakah modul RFID reader dapat membaca RFID tag sesuai dengan fungsinya. Modul RFID akan menyala setelah dimasukkan tegangan input sebesar 3,3V, kemudian arahkan kartu ke modul RFID dan amati nomor seri kartu pada serial monitor Arduino.

Pengujian pertama pada RFID reader adalah dengan melakukan pembacaan tag dengan variasi jumlah tag. Jumlah tag yang digunakan ada 3 dengan hasil pembacaan id kartu:
1. Tag A : DEBEC9F0

2. Tag B : 099B39AC

3. Tag C : 72DD40D5

\section{a. Pembacaan RFID Tag pada Serial Monitor}

Gambar berikut menunjukkan percobaan dengan pembacaan RFID tag $\mathrm{A}, \mathrm{B}$, dan $\mathrm{C}$ sebanyak sepuluh kali pembacaan.

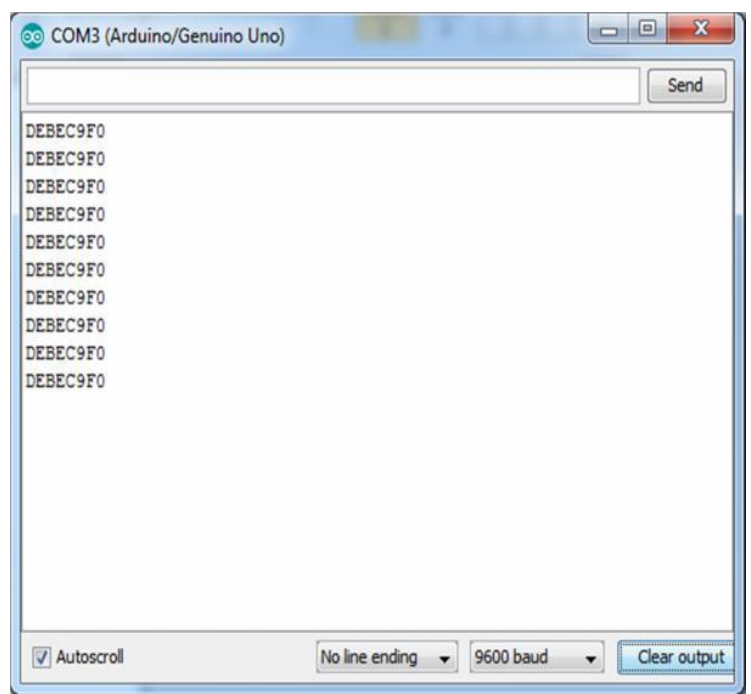

Gambar 15. Pengujian RFID Tag A

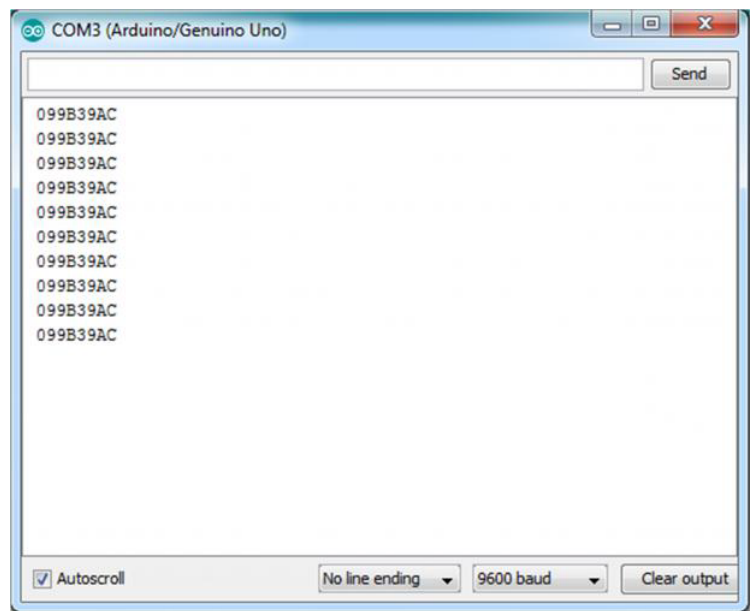

Gambar 16. Pengujian RFID Tag B 


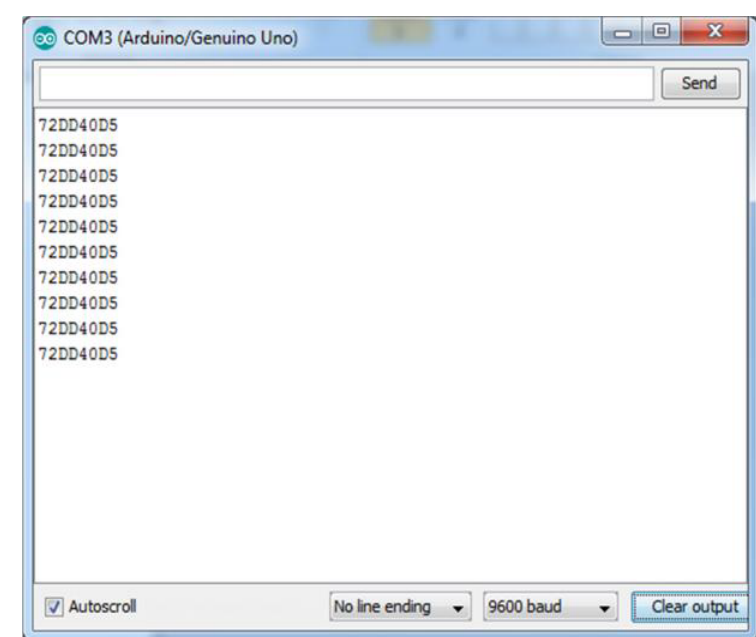

Gambar 17. Pengujian RFID tag C

\section{b. Pengujian RFID terhadap Jarak}

Pengujian kedua dilakukan untuk mengetahui tingkat sensitifitas pembacaan RFID reader terhadap jarak. Untuk pengujiannya RFID tag didekatkan pada RFID reader pada jarak yang berbeda-beda tanpa penghalang. Tabel 1. menunjukkan percobaan mendeteksi RFID tag pada berbagai macam jarak.

Tabel 1. Pembacaan RFID Tag pada Jarak Tertentu

\begin{tabular}{|c|c|}
\hline Jarak $(\mathrm{cm})$ & Status \\
\hline 1 & Terbaca \\
\hline 2 & Terbaca \\
\hline 3 & Terbaca \\
\hline 4 & Terbaca \\
\hline 5 & Terbaca \\
\hline
\end{tabular}

\section{Hasil pengujian Sensor Inframerah}

Sensor inframerah berperan penting pada alat ini. Sensor inframerah akan mengontrol pergerakan lift secara otomatis berdasarkan pendeteksian kendaraan yang melewatinya. Modul inframerah yang digunakan adalah IR-FC51.

Pada pengaplikasiannya ke arduino modul ini terhubung ke port analog, akan tetapi dapat diberi masukkan berupa data digital.

Pengujian tegangan keluaran ini bertujuan untuk memastikan apakah kedua unit sensor inframerah layak pakai agar alat ini dapat berjalan sesuai dengan perencanaan yang ada serta untuk mengetahui tegangan keluaran yang dihasilkan.

Pengujian dilakukan dengan cara mendekatkan objek sejauh maksimal $4 \mathrm{~cm}$ dari sensor.

\section{a. Pengujian Sensor Inframerah pada Serial Monitor}

Pengujian ini dilakukan dengan cara mengamati reaksi sensor inframerah pada serial monitor pada aplikasi Arduino IDE. Ada dua kondisi yang harus diamati yaitu ketika sensor mendeteksi keberadaan objek dan ketika tidak mendeteksi adanya objek.

Pengujian ini bertujuan untuk mengamati nilai level tegangan digital pada arduino. Hal ini dilakukan karena masukan dari sensor inframerah adalah sinyal analog, namun pada arduino akan dikonversi menjadi data digital.

Angka yang diperoleh nantinya akan dibandingkan dengan pengukuran dengan menggunakan multimeter. Selanjutnya data yang diperoleh tersebut akan diperbandingkan dengan menggunakan persamaan matematika untuk mengubah nilai level tegangan pada serial monitor ke nilai analog seperti yang diperoleh pada data multimeter.

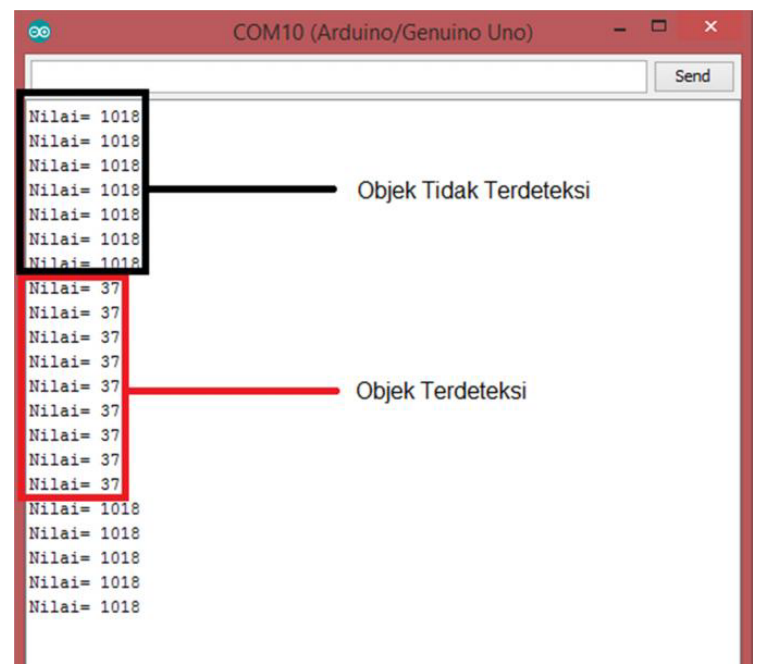

Gambar 18. Hasil Pengujian Sensor "A" pada Serial Monitor 


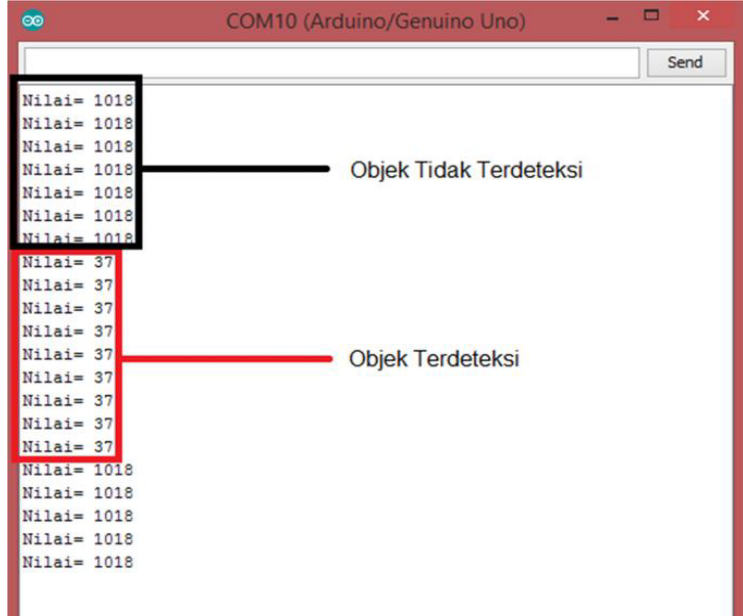

Gambar 19. Hasil Pengujian Sensor "B" pada Serial Monitor

\section{b. Pengukuran Tegangan Keluaran pada Sensor Inframerah}

Pengujian ini dilakukan dengan cara mengamati nilai tegangan keluaran sensor inframerah pada multimeter baik pada keadaan terhalang atau tidak terhalang. Sama seperti proses pengambilan data pada serial monitor, pengujian ini juga dilakukan pada kedua sensor inframerah yang digunakan

Tabel 2. Pengujian Sensor Inframerah "A"

\begin{tabular}{|l|c|}
\hline \multicolumn{1}{|c|}{ Kondisi } & Tegangan Output (V) \\
\hline Mendeteksi kendaraan & 0,2 \\
\hline Tidak Mendeteksi & 4,7 \\
\hline
\end{tabular}

Tabel 3. Pengujian Sensor Inframerah "B"

\begin{tabular}{|l|c|}
\hline \multicolumn{1}{|c|}{ Kondisi } & Tegangan Output (V) \\
\hline Mendeteksi kendaraan & 0,2 \\
\hline Tidak Mendeteksi & 4,7 \\
\hline
\end{tabular}

\section{Analisis Sistem}

Setelah data pengujian diperoleh, tahap selanjutnya adalah menganalisis data tersebut. Analisis dilakukan sebagai langkah untuk memastikan apakah semua komponen penyususn prototype ini berjalan sesuai fungsinya.

\section{Analisis Hasil Pengujian RFID}

Dari pengujian RFID diatas dapat dilihat bahwa pembacaan terhadap tag yang didekatkan ke RFID reader akurat dengan jarak maksimal $5 \mathrm{~cm}$. Lebih dari jarak itu maka pembacaan ID dari tag tidak beraturan. Dari pengujian terhadap jarak tanpa penghalang. Penulis juga melakukan pengujian dengan penghalang kertas, RFID reader masih bisa membaca kode seri RFID tag karena sinyal yang dikirimkan dan sepenuhnya diterima oleh RFID reader ,sementara itu ketika diberi penghalang tripleks, jarak maksimum agar modul RFID dapat membaca kode kartu adalah $3 \mathrm{~cm}$, dan ketika diberi penghalang besi atau logam, modul RFID tidak dapat membaca kode kartu karena gelombang yang dikirimkan dipantulkan kembali. Apabila RFID tag didekatkan pada modul pembaca RFID, nantinya arduino akan mendeteksi apakah kode kartu sudah terdaftar atau belum. Hanya kartu yang sudah didaftarkan sebagai pemilik kendaraan yang memiliki akses masuk kedalam basement.

Apabila kartu yang didekatkan tidak terdaftar didalam sistem, maka akses masuk ke basement tidak diterima. Hal ini bermanfaat sebagai langkah pencegahan terhadap tindak kriminal pencurian kendaraan bermotor dimana akses menuju parkir kendaraan yang begitu mudah.

Dengan tidak adanya bit loss pada saat pentransmisian data dari reader, dapat dikatakan rangkaian RFID dapat bekerja dengan baik dan memenuhi standar yang diinginkan untuk sistem parkir ini.

\section{Analisis Pengujian Sensor Inframerah}

Sensor inframerah ini bekerja dengan cara memanfaatkan photo diode atau dioda cahaya. Pada prototype ini sensitifitas sensor diperkecil menjadi $3 \mathrm{~cm}$ saja agar pendeteksian dilakukan ketika kendaraan benar-benar melaui sensor.

Gambar 19 menunjukkan nilai intensitas cahaya pada sensor inframerah yang ditampilkan pada serial monitor. Sensor ini hanya mendeteksi dua kondisi yaitu ketika mendeteksi adanya objek dan ketika tidak mendeteksi objek. Karena hanya diberikan dua kondisi yaitu "high" dan "low", maka nilai intensitas cahaya 
yang ditampilkan adalah 37 dan 1018 . Ketika sensor inframerah mendeteksi objek di depannya nilai pada serial monitor menunjukkan angka 37, sementara ketika tidak terhalang nilai intensitas cahayanya adalah 1018.

Angka tersebut berasal dari nilai digital yang di baca oleh arduino. Di dalam papan mikrokontroler arduino terdapat Analog to Digital Converter (ADC) $10(2=1024)$ bit. Jika dihitung dengan persamaan matematika, maka nilai tegangan keluar dapat dituliskan dengan:

Vout $=$ Nilai Konversi ADC x ( Vin / 1024 )

Dengan persamaan tersebut, maka diperoleh hasil sebagai berikut:

* Jika mendeteksi objek

$$
\begin{aligned}
& =37 \times(5 / 1024) \\
& =37 \times 0.0048828125 \\
& =0,18 \mathrm{~V} \\
& \text { *Jika tidak mendeteksi objek } \\
& =1018 \times(5 / 1024) \\
& =1018 \times 0.0048828125 \\
& =4,97 \mathrm{~V}
\end{aligned}
$$

Berdasarkan gambar 18 dan 19 dengan tabel 2 dan tabel 3, bisa dicermati bahwa tegangan keluaran pada sensor inframerah akan menurun ketika mendeteksi adanya objek. Sebaliknya, ketika sensor tidak mendeteksi keberadaan objek maka tegangannya akan tetap berada di kisaran 5V. Sensor akan dapat bekerja sebagai pengontrol masukan ke motor dc ketika nilai konversi intensitas cahaya digitalnya adalah 37 .

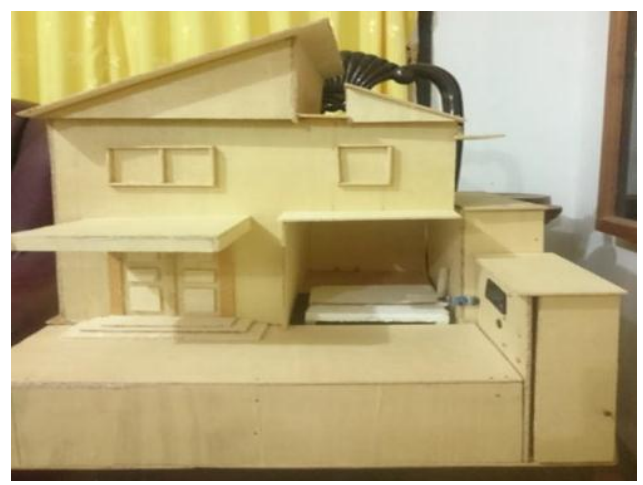

Gambar 20. Hasil akhir pembuatan prototype

\section{SIMPULAN}

Setelah dilakukan perancangan, pembuatan, pengujian dan analisis pada penelitian ini, dapat diambil disimpulkan:

1. Prototype ini dibuat dengan tujuan untuk mengoptimalkan area sempit sebagai tempat parkir dengan memindahkan tempat parkir kendaraan bermotor ke dalam basement menggunakan lift.

2. Selain sebagai peningkatan efektifitas penggunaan lahan, prototype ini dapat meningkatkan keamanan kendaraan dari faktor kriminal dan lingkungan. Dengan menggunakan kartu identitas pemilik kendaraan, hanya yang memiliki akses khusus yang dapat masuk ke area basement. Selain itu kendaraan akan aman dari faktor lingkungan seperti banjir, badai, pohon tumbang, dan sebagainya.

3. RFID mempunyai nomor seri yang berbeda-beda untuk membedakan tiap anggota parkir dengan jarak pembacaan maksimal $5 \mathrm{~cm}$ dan memanfaatkan Arduino sebagai pengolah datanya.

4. Sensor inframerah dapat bekerja dengan jarak jangkauan tertentu sesuai kebutuhan. Hasil deteksi sensor inframerah pun dapat dijadikan masukan bagi kontrol motor DC.

5. Keseluruhan input akan berujung pada keluaran pergerakan motor dc sebagai lift.

\section{SARAN}

Dalam pembuatan penelitian sistem parkir cerdas ini penulis merasa masih jauh dalam kata sempurna. Kekurangan dari tugas akhir ini terletak pada sistem otomasi pergerakan motor dengan menggunakan sensor inframerah dinilai kurang efektif karena sensor ini tidak dapat membedakan objek padat yang melintas didepannya. Oleh karena itu penulis menyarankan agar adanya pengembangan dari prototype parkir cerdas ini agar lebih baik kedepannya 


\section{DAFTAR PUSTAKA}

[1] Bishop Owen. 2004. Dasar-dasar Elektronika. Erlangga. Jakarta.

[2] Instrument Otomasi Industri. (2014). Pengertian motor DC dan jenis motor DC. Ditelusuri 25 September 2017.

http://www.insauin.blogspot.co.id/.

[3] Kadir, Abdul. 2014. Buku Pintar Pemrograman Arduino. Yogyakarta. Mediacom.

[4] Kuswadi, Son. 2007. Kendali Cerdas, Teori dan Aplikasi Praktisnya. Yogyakarta. Andi Offset.

[5] Munandar, A. (2012). Les Elektronika. Ditelusuri 2 September 2017. http://www.leselektronika.com/.

[6] Putra, Ferdi Perdanna. 2015. "Rancang Bangun Prototype Sistem Parkir Mobil Menggunakan Rfid Berbasis Arduino Uno". Tugas Akhir. Padang: Politeknik Negeri Padang.

[7] Widodo Budiharto, Elektronika Digital Dan Micprosesor, Andi Offset Yogyakarta, 2004. 